\title{
Preoperative experience and postoperative fluid preference in adrenalectomized rats'
}

DOUGLAS L. GRIMSLEY, ${ }^{2}$ HUMAN RESOURCES RESEARCH OFFICE, Presidio of Monterey, Calif. 93940 AND JOSEPH W. CULLEN, FLORIDA STATE UNIVERSITY, Tallahassee, Florida

Rats given the opportunity to establish a strong preference for sugar over salt were compared following adrenalectomy with rats receiving only distilled water preoperatively. There were no differences between groups in $\mathrm{NaCl}$ ingested though adrenalectomized animals drank significantly less sucrose as compared to sham operated Ss. Development of a preoperative preference for sugar over salt is not a sufficient condition to prevent the typical postoperative increase in salt intake by adrenalectomized rats.

The loss of sodium via the urine following adrenalectomy in the rat is associated with an increase in salt appetite. If the adrenalectomized rat is placed in a free-choice situation where a saline solution and a water solution are the only two liquids available, within certain concentration limits, the rat will significantly choose the salt solution. Richter (1947) concluded from several studies that when a "need" develops for a particular dietary item, the rat develops a "specific hunger" for the required substance.

Others have shown that compensatory appetitive choices do not necessarily occur following a deficiency (Scott \& Verney, 1947). Harriman (1955) supported this position by showing that rats, given the opportunity to establish a preoperative preference for sugar over salt, maintain that preference subsequent to adrenalectomy and fail to manifest the expected increase in salt consumption. Even with sodium chloride $(\mathrm{NaCl})$ readily available, several adrenalectomized rats died and the survivors showed marked weight losses.

Since the results obtained by Harriman and others contradict much of the current evidence about salt seeking in the adrenalectomized rat and question the validity of the specific hunger hypothesis, additional investigation seemed warranted.

Subjects and Apparatus

The 40 male albino rats (Dublin Lab, Dublin, Virginia) weighed 200-260 $\mathrm{g}$ at the start of experimentation.

All Ss were maintained on a Na deficient diet (Hartroft formula, General Biochemicals) which contained $4.3 \mathrm{mg}$ of $\mathrm{Na}$ per $100 \mathrm{~g}$. Food was presented in an aluminum cup fastened at the rear of the cage.

The experimental animals received sugar and salt solutions preoperatively while the controls received only distilled water. Concentrations of $0.9 \% \mathrm{NaCl}$ and $9.4 \%$ sucrose were chosen because of their identical osmotic pressure and their isotonic relationship to body fluids. Solutions were mixed on a weight/ volume basis with distilled water as the solvent. These solutions were presented in two graduated tubes fastened to the cage front so that their stainless steel drinking spouts extended into the cage about 3 in. apart. To control for position habits and the preference for a given drinking spout, each fluid was presented in each position in each container (Bare, 1949).

Procedure

The $40 \mathrm{Ss}$ were randomly divided equally between two conditions. Food and liquids were freely available and intake was measured daily. Body weights were determined on alternate days.

Condition 1. Groups 1 and $2(\mathrm{~N}=10$ per group) received both $\mathrm{NaCl}$ and sucrose during the 19 preoperative days (Experience Groups). On Day 20, the animals of Group 1 were bilaterally adrenalectomized and those of Group 2 received sham surgery. (Sham surgery consisted of bilateral incisions and exposure of the adrenals, but they were not removed.) Both groups continued to receive the $\mathrm{NaCl}$ and sucrose solutions for the 32 postoperative days.

Condition 2. The remaining 20 Ss (Groups 3 and 4) received only distilled water during the preoperative period (No Experience
Groups). On Day 21, the animals of Group 3 were bilaterally adrenalectomized and the animals of Group 4 were sham operated $(\mathrm{N}=10$ per group). Postoperatively, these Ss were given access to the $\mathrm{NaCl}$ and sucrose solutions.

Postmortem verification of adrenalectomy was gained at the end of the experiment.

Results

Thirty-five animals survived surgery. Postoperatively Groups 1-4 had $10,8,9$, and 8 Ss respectively.

Sucrose consumption is displayed in Fig. 1 and shows considerable differentiation as a function of treatment. The difference between the sham and adrenalectomized groups over the first 16 days was significant at the .001 level $(F=13.79$, $\mathrm{df}=3 / 31)$. Beginning at about Day 21 and by Day 32, all groups were similar in sucrose ingestion.

Figure 2 shows the mean $\mathrm{NaCl}$ intake for all groups over the 32 postoperative days. In general, the adrenalectomized groups consumed greater quantities of $\mathrm{NaCl}$ than did the sham animals. However, the difference was not quite greater enough to be statistically significant at the .05 level.

During the first 16 postoperative days, there was, for all groups, a gain in weight significant at the .001 level $(F=116.81$, $\mathrm{df}=6 / 186$ ). There were no significant differences between the groups, however.

The analysis of food consumption for the four groups showed much overlap between groups and no consistent differences between or within groups.

Discussion

The results of this experiment show that adrenalectomized rats with an established preference for sucrose do not maintain a low $\mathrm{NaCl}$ consumption following adrenalectomy. Contrary to Harriman's results (1955), they drank approximately the same quantities of $\mathrm{NaCl}$ and sucrose as adrenalectomized rats with no selective experience.

The fact that all animals ingested equivalent amounts of salt is due to the choice of the concentration used. For the shamoperated animals, a $0.9 \% \mathrm{NaCl}$ solution is very near optimal palatibility (Young \& Falk, 1956). The adrenalectomized animals, meanwhile, had to drink enough to maintain life and, as evidenced by significant weight gain and the absence of any deaths, this was done quite adequately.

In a study recently published by Grimsley Fisher (1967), another test was made of whether an established feeding habit would persist regardless of bodily needs. Drinking behaviors of

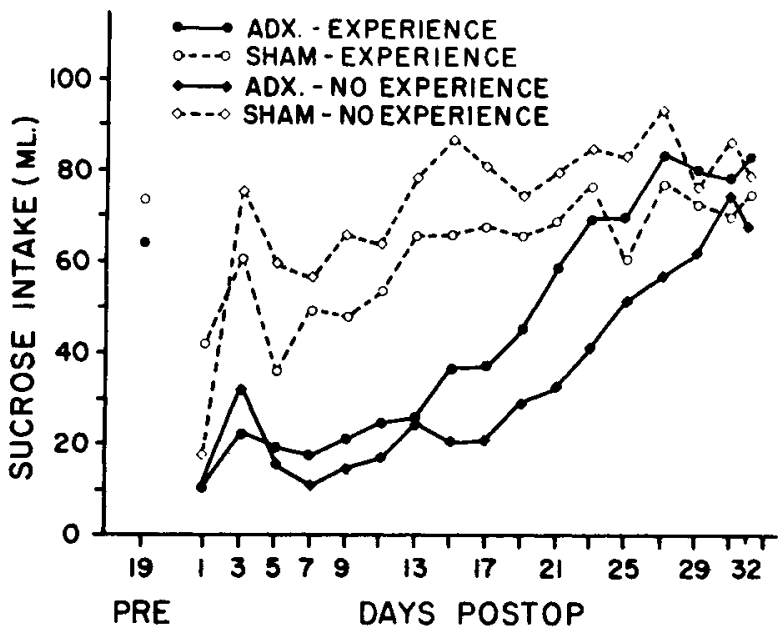

Fig. 1. Mean sucrose intake for the final preop and the 32 postop days. 


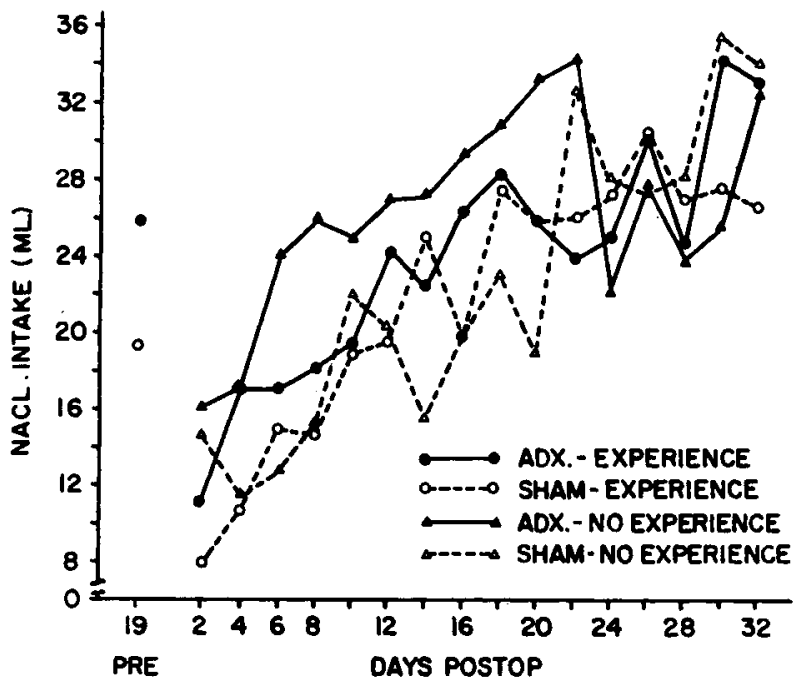

Fig. 2. Mean $\mathrm{NaCl}$ intake for the final preop and the 32 postop days.

adrenalectomized and sham-operated rats were compared under preoperative conditions of saccharine and salt solutions, or only distilled water, available. Saccharine experience did not contribute to a significant change in postoperative drinking behavior; adrenalectomized Ss, regardless of experience, drank less saccharine solution than sham Ss, and all groups consumed similar amounts of $\mathrm{NaCl}$.

The animals in Harriman's study may have been catering to another regulatory process, namely, increased sugar seeking as a consequence of the hypoglycemia produced by adrenalectomy (Long, Katzin, \& Fry, 1940). It is not clear why his animals should regulate with respect to blood sugar levels when generally it seems that electrolyte balance is of overriding importance. To answer the question of whether hypoglycemia produced by adrenalectomy is affecting solution preference, we are currently analyzing blood and urine glucose levels.

Based upon the results of the present study and evidence obtained earlier, it can be concluded that development of a preference for sugar over salt is not a sufficient condition to prevent the typical postoperative increase in salt intake by adrenalectomized rats.

\section{REFERENCES}

BARE, J. K. The specific hunger for sodium chloride in normal and adrenalectomized rats. J. comp. physiol Psychol, 1949, 42, 242-253.

GRIMSLEY, D. L., \& FISHER, L. E., JR. Preoperative saccharine experience and postoperative fluid preference in adrenalectomized rats. Psychon Sci, 1967, 9, 299-300.

HARRIMAN, A. E. The effect of a preoperative preference for sugar over salt upon compensatory salt selection by adrenalectomized rats. $J$. Nutrition, 1955, 57, 271-276.

LONG, C. N., KATZIN, B., \& FRY, E. G. The adrenal cortex and carbohydrate metabolism. Endocrinology, 1940, 26, 309-344.

RICHTER, C. P. Biology of drives. J. comp. physiol. Psychol, 1947, 40, 129-134.

SCOTT, E. M., \& VERNEY, E. L. Self selection of diet. IV. The nature of appetites for B. vitamins. J. Nutrition, 1947, 34, 471-480.

\section{NOTES}

1. This research was supported in part by the Research Participation Program for College Teachers of the National Science Foundation and by Grants MH 11281-01 and MH 11906-01 from the National Institute of Mental Health.

2. The data for this report were collected at Florida State University, with the assistance of Mr. Joseph Cullen. 